Literatura y Lingüística $\mathrm{N}^{\circ} 26$

ISSN 0716-5811 / pp. 61-80

\title{
El juego como proyecto vital de los protagonistas de Háblame de Laura, de Egon Wolff
}

\author{
Jorge Rueda C.*
}

\section{Resumen}

El artículo describe y explica la manera cómo los protagonistas de la obra conforman, a partir de las categorías centrales del juego, una conciencia específica de segunda realidad -lúdica- o de franca irrealidad en relación con las circunstancias ordinarias y con la historia de abandono y frustración que sus vidas representan.

Palabras clave: Juego, irrealidad, 'mimicry'.

\section{Play as a vital project of protagonists of Háblame de}

\section{Laura by Egon Wolff}

\section{Abstract}

This article describes and explains how the protagonists of this play build up, as from the main categories of play, a specific conscience of a second reality -playful- or of a downright unreality, in relation to the ordinary circumstances and with the story of abandonment and frustration that their lives represent.

Key words: Play, unreality, 'mimicry'.

Recibido: 09-04-2012 Aceptado: 20-07-2012

Doctor en Estudios Americanos, mención Pensamiento y Cultura. Académico facultad de Humanidades de la Universidad de Santiago de Chile. Chile. jorge.rueda@usach.cl 
El juego como proyecto vital de los protagonistas de Háblame de Laura, de Egon Wolff / Jorge Rueda

En último extremo no existe el juego en solitario. Para que haya juego, aun en ausencia de otro jugador real, tiene que haber algún 'otro' que juegue con el jugador y que responda a la iniciativa del jugador con sus propias contrainiciativas.

Hans-Georg Gadamer

\section{Presentación}

En general, la dramaturgia del chileno Egon Wolff (1926) ha sido críticamente caracterizada como la expresión de la temática del dominio. Materializada a través de los proyectos y acciones de sus protagonistas, esta noción central se encarna en la lucha espectacularizada que, casi siempre, desarrollan a partir de impulsos egoístas o determinados por el peso de las creencias y acciones institucionalizadas. Buscan, en efecto, el control, la posesión psicológica y la manipulación de otros ${ }^{1}$. En este sentido, las extravagancias alienadas y obsesiones de los dominantes se imponen por sobre los temores y debilidades de los sometidos. Estos últimos, neutralizados y sin voluntad, se abandonan a y se alimentan de -como una necesidad- las reglas de un ritual de pesadilla: la imposibilidad de abandonar la dominación. Las referencias a este ceremonial aluden a un doloroso sistema "lúdico" en el cual las unidades representadas se construyen a partir de la repetición de situaciones dramáticas provocadoras de la victimización psíquica de los anulados. ¡Vaya juego!

Precisamente, la alternativa de incorporar la dinámica del juego, como componente de base de las acciones y de las prácticas comunicativas de muchos de los personajes de Wolff, amplía el conocimiento y explicación del mundo dramático creado por el autor. Como una manera de apuntar algunos indicios en la demostración de esta hipótesis, el presente artículo lo asume como desafío. En particular, la creación dramática Háblame de Laura (estrenada por el Teatro de la Universidad Católica en 1986)²,

1 Tan solo como un ejemplo, ya en 1970 el escritor y crítico Antonio Skármeta escribió: "Una generalizada incapacidad de vivir espontáneo, una tensa avidez por conseguir seguridades, una compulsiva manera de vivir la ambigüedad real-irreal, lleva a los personajes de Wolff a identificarse entre ellos en relaciones de dominio. Al no ser capaces de entregarse a la práctica de una existencia marcada por la espontaneidad, al fallar en el control del instintivo goce de vivir de los seres más primarios, recurren en última instancia al chantaje sentimental. Así el dominio de un ser les da la fugaz impresión de ser alguien". En "La burguesía invadida: I. Egon Wolff", Revista Chilena de Literatura No 4 (Otoño 1971), p. 91.

2 Durante el período comprendido entre el 23 de junio y el 6 de agosto de 2011, la obra fue nuevamente representada en el Teatro Mori Bellavista de Santiago de Chile. Precisamente esta reposición motivó la redacción del presente artículo.

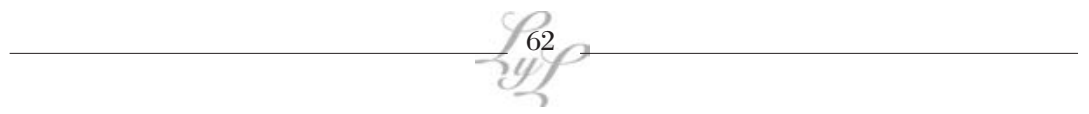


describe la vida de dos personajes: Alberto -Momo- y su madre, Cata. Ambos movilizan verdaderos rituales de enajenación, donde el fundamento final se consume en la despersonalización de los protagonistas ${ }^{3}$. Acorralados en un deteriorado departamento, la existencia rutinaria y decadente que las figuras del texto exhiben, y que equivale a la fuerza dominadora, se vitaliza tan solo por las fantásticas historias y las abusivas bromas que respectivamente se cuentan y se representan. Esta dimensión lúdica, único elemento excitante en la vida de los personajes, se impone a lo largo de la obra como un juego: frente a la condición carente de perspectivas y hasta enajenada de Alberto y Cata, se proyectan, a nivel de enunciación, situaciones imaginadas, las cuales les permiten el distanciamiento del presente que habitan y/o el escape intermitente respecto de la hostilidad que asedia sus existencias.

Como efecto de lo anterior, el texto muestra una anécdota mínima, que permanece estática: la llegada de Alberto al departamento, después de la jornada de trabajo (vendedor en una tienda de zapatos). De aquí que el comentario que se presenta a continuación descansa sobre la siguiente premisa: el funcionamiento dramático del texto Háblame de Laura encuentra su singularización en categorías provenientes del código del juego. La metodología de análisis, por ende, resolverá, en cuanto instrumento operacional, cuáles son las señales patentes de la acción discursiva de los personajes que evidencien las categorías propias del juego. La tarea central del presente ensayo se traduce en demostrar que el proyecto comunicativo de los protagonistas -en cuanto interlocutores- mantiene a lo largo del texto una situacionalidad discursiva que se desarrolla en función del principio de la descomposición de la realidad. Este eje regulador posibilita la instauración del juego como expresión pragmática y simbólica que niega el entorno.

3 A propósito de la temática de la dominación, Consuelo Morel escribió en el año 1988: "Háblame de Laura puede ser vista como una gran metáfora de la relación de dos seres humanos que viven solos, encerrados y, al parecer derrotados por la vida. En otras palabras, es posible ver a Cata y Alberto comos dos frustrados por la sociedad, producto de su falta de perspectivas". En "Háblame de Laura: Estructura dramática circular y pulsión a la repetición", Revista Apuntes de Teatro No 96 (Otoño 1988), p 119. Veinte años después, Sol E. Díaz comentó acerca de los protagonistas de Háblame de Laura: "Son seres inacabados complementándose en su frustración, atados por sus recuerdos, por sus planes truncados, por su miedo que los lleva a enrostrarse cuanto daño se han hecho, se hacen y como uno al otro se impiden avanzar, pasando de la bofetada e insulto al ilícito coqueteo y caricia. Son parásitos sociales, morales y psicológicos, en una simbiosis enfermiza en que no sabemos cuánto de lo expuesto como verdad lo es, lo que sí queda claro es que lentamente saborean su actuar como una venganza contra sí mismos". (http://trinidaddecuatroesquinas.blogspot.com/2008/12/hablame-de-laura-y-la-tragedia-de-lo. html) 
Complementariamente, se revelará cómo la acción lúdica que Alberto y Cata sostienen en sus discursos es una forma de ocupación vital donde las leyes e instituciones de la vida social quedan reemplazadas, en el espacio y en el tiempo al interior del cual se efectúa el juego, por otras cuyo fundamento se traduce en el proyecto de evadir aquella realidad que a los protagonistas les remite al fracaso. En este sentido, cobra importancia el pensamiento de J. Huizinga cuando precisa: "El juego es una acción acompañada de una sensación de tensión y de júbilo, y de la conciencia de ser otro modo que en la vida real". (58)

\section{Análisis}

La relación que se hace del juego como categoría articuladora de la obra seleccionada se ajusta precisamente a la condición existencial frustrada de sus protagonistas. En efecto, en función de esto último, madre e hijo echan las bases para construir un espacio delimitado especialmente para el desarrollo de lo lúdico. En más de una oportunidad, los hablantes adoptan una modalidad enunciativa cuyo índice recurrente es la necesidad de sostener una enunciación disfuncional, en el sentido de no comunicarse contenidos de verdad ${ }^{4}$ :

Alberto: ¿Quieres que te siga contando...?

Cata: Siempre que sea verdad.

Alberto: ¿Qué crees tú?

Cata: Que es mentira.

Alberto: Bueno... es mentira, y todos contentos. ¿Para qué quieres

la verdad? Es lata. Sólo la mentira es excitante y entretenida. (134)

Como ley o principio reiterado de sus enunciados, Alberto profiere un discurso transgresor de la realidad y que Cata, poco a poco, aprehende. De este modo, Alberto se vuelve un factor activo respecto de la labor de instaurar una atmósfera de base lúdica que les permita a ambos deslindar la realidad que les enrostra fracaso y degradación. Entre estos límites, la reflexión de Roger Caillois constituye la remisión teórica sobre la cual descansa el siguiente análisis. Cuatro son los principios capaces, según Caillois, de crear la variedad de juegos y que vienen de poderosos instintos humanos como la competencia, la persecución de la suerte, el simulacro y el goce por experimentar el vértigo:

4 Para el análisis, se seguirá la edición de Háblame de Laura impresa en Revista Apuntes de Teatro, No 96, otoño 1988. Publicación semestral de la Escuela de Teatro de la Pontificia Universidad Católica de Chile, pp. 125 - 172.

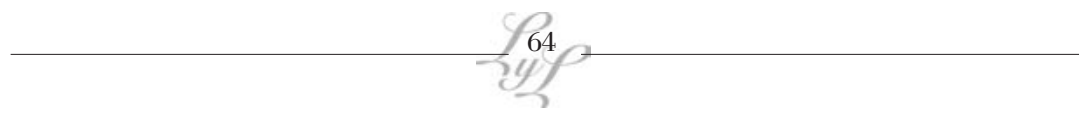


Las actitudes que empujan a adoptar tal juego o tal especie de juego con preferencia a tal otra son: la ambición de triunfar en una competición reglamentada gracias al solo mérito de los participantes (agôn); la dimisión de la voluntad en provecho de una espera ansiosa y pasiva de la sentencia de la suerte (alea), la ilusión de vivir un universo imaginario que es ficticio (mimicry), en fin, perseguir el vértigo (ilinx). (62)

Sin duda que la categoría que se aviene con los propósitos de este artículo es la 'mimicry'. En esta, el jugador-participante evade el mundo haciéndolo diferente o haciéndose, el sujeto, otro. A esto responde la aportación de Callois: "[En la mimicry] uno se encuentra entonces frente a una serie variada de manifestaciones que tienen como carácter común descansar sobre el hecho de que el sujeto juega a hacer creer a los demás que él es distinto de sí mismo; olvida, disfraza, se despoja de su realidad para fingir otra" (36). En adelante, se mostrarán las diferentes formas con las que la actividad discursiva de los personajes configura una dimensión lúdica que tiene como base la mecánica de la 'mimicry'. Esto último, en cuanto posibilidad neutralizadora de la realidad. En determinados momentos del análisis, esta categoría de base se verá integrada al 'ilinx', la cual, complementa Caillois, "consiste en una tentativa por destruir por un instante la estabilidad de la percepción e infligir a la conciencia lúdica una especie de espasmo, de trance o de aturdimiento que aniquila la realidad con una soberana brusquedad" (42). Se aclara que, para efectos de esta propuesta, tal especie de trance o aturdimiento será entendido no tanto como un vértigo físico, sino como un arrebato que pone en paréntesis el orden establecido, como un éxtasis que colma a los hablantes y que los lleva a un estado cercano a la enajenación.

\section{La instauración de lo lúdico en Cata}

En reiterados momentos del texto, la acción discursiva de este personaje contribuye al proyecto de configurar lo lúdico. En particular, la categoría deíctica del tiempo verbal deja en evidencia este objeto. Se sabe que el rasgo esencial del tiempo en una situación de enunciación es que pone en relación "el tiempo de la acción, suceso o estado que refiere el discurso, con el tiempo de la enunciación, que corresponde al ahora" (Reyes, 117). Se trata, en efecto, de reconocer cuál es el tiempo, en el valor deíctico del decir de la mujer, que se desliza hacia el terreno de lo irreal, del simulacro, de la 'mimicry'. 
El pasado, en la narrativa que revela un mundo y, por ende, una existencia, se contrapone al presente. En Cata, este último es la expresión enunciativa de lo sórdido que predetermina la vida del personaje. Alejarse de tal condición compromete en la actividad discursiva del hablante la permanente utilización del pretérito. Se trata de la modalización capaz de instaurar en ella la 'mimicry'. Precisamente, cuando la crudeza del presente más la golpea, le grita a Alberto: "¿Y qué es lo que quieres ahora?" (149). Manifiesta, con esto, la clara percepción de la realidad que la aplasta y la angustia: "¿Quieres que declare que eres un fracaso? ¿Crees que eso nos hará sentir mejor a los dos?" (149). Estas expresiones, que acusan el presente de los personajes, enseña la condición disminuida de la madre: "Momo, no nos sintamos más miserables de lo necesario, ¿no crees? Vamos, contémonos algo divertido!" (150). De una significancia primordial para los propósitos del presente artículo, resulta esta última cita porque descubre la posición discursiva de Cata. En oposición al presente miserable, la hablante manifiesta de manera explícita la necesidad de divertirse. Importa recalcar que la categoría del juego se configura en la situacionalidad comunicativa del texto y como aspecto subsidiario, en este caso, de la necesidad de Cata por evadir el presente.

Ahora bien, la posibilidad concreta, capaz de regular el anhelo de la mujer, descansa en la misma actividad discursiva de ambos, en cuanto interlocutores: "Contémonos algo...!". Se trata de la conminación a realizar un tipo de acto de habla, cuyo carácter, del tipo expositivo, lo proporciona el verbo contar. Alberto, persuadido, entra en el juego: “...A ver, cuéntame: ¿cómo eras de joven?" (151). Y Cata, animada, refiere:

Era bonita... Como ya te he dicho otras veces, era una joven muy agraciada... Estaba con mis padres. Hacíamos un viaje a las islas. Una orquesta tocaba en cubierta. Paseaban muchas señoras de blanco, con sus niños celestes y sus niñeras de azul... De pronto, una gaviota se paró sobre una de las jarcas que sujetaban un bote. $(151,152)$

Dos aspectos llaman enormemente la atención. En primer término, Cata expone una historia del pasado, por consiguiente, la opción de divertimiento es un efecto del discurso, es pura enunciación. En segundo lugar, la acción comunicativa de la mujer opone, al presente, un decir en pasado. Si examinamos la cita en un afán por identificar la categoría deíctica que descubra la necesidad de la mujer por evadir la realidad inmediata, se descubre la notoria preponderancia del tiempo verbal en pretérito. En este ardid enunciativo, parece radicar el goce y la diversión para los interlocutores. Alberto así lo manifiesta, como consecuencia

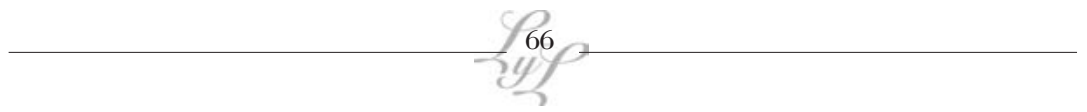


del acto de habla de Cata: "Oh, Dios mío, di eso de nuevo" (152). Y complementa aún más: "Oh Dios, cómo me gusta la manera como lo dices" (152). Lo subrayado por el autor del presente ensayo acusa que la naturaleza del elemento provocador del efecto perlocutivo en el oyente es genuinamente discursivo: el verbo "decir". Pero aquello que corresponde, ahora, preguntar es lo siguiente: ¿De qué manera este discurso en pasado soslaya el presente y desliza a quien lo profiere al plano de la irrealidad, de la simulación, de la 'minicry'?

Nueve son los verbos que utiliza el hablante en la cita comentada; el tiempo de todos corresponde al pretérito. En él, se configura un índice ostensiblemente clave: el pretérito imperfecto. Este factor -siete imperfectos y dos perfectos- no es único e irrepetible en la enunciación de Cata, como se mostrará en otros ejemplos. Sin embargo, como recién se apuntó, preocupa estudiar básicamente qué interrelación se establece entre el imperfecto, como pasado que lógicamente se opone al presente, con la dimensión lúdica de la 'mimicry'. Acorde con Roland Barthes:

El imperfecto es el tiempo de la fascinación: parece estar vivo y sin embargo no se mueve: presencia imperfecta, muerte imperfecta; ni olvido ni resurrección; simplemente el señuelo agotador de la memoria. Desde el origen, ávidas de representar un papel, las escenas se ponen en posición de recuerdo: frecuentemente lo siento, lo preveo, en el mismo momento en que se forman. (213)

"El imperfecto es el tiempo de fascinación", y con el imperfecto Cata recuerda ¿lo vivido o lo soñado? Difícil deslindarlo. El aspecto fundamental es que en el discurso de ella importa el escurrimiento, la aspiración de escabullirse a otros planos posibles, mediante el valor modal que le ofrece pragmáticamente el imperfecto. Las situaciones así evocadas suceden, transcurren y suscitan la posibilidad de sobrepasar lo vivido en el presente inmediato; el imperfecto, que impregna la enunciación de Cata -en respuesta a la necesidad de evadir la adversidad (“...no nos sintamos más miserables!", 150)- es el índice conformador del efecto que este artículo desea comprobar: el hablante aleja la acción del "ahora" $\mathrm{y}$, de paso, logra alejarse de este, recurriendo a un pasado que establece la divergencia absoluta con la miseria existencial de la realidad que le compromete. En este contexto, el imperfecto des-realiza el entorno: "Es como si de repente la pieza se me llenara de olor a brea, a algas, a estrellas de mar!" (152). Y logra la 'mimicry' cuando reviste a Cata de una figura luminosa, dichosa y bella: el reverso de su presente: "Era bonita... era una joven muy agraciada. Hacíamos un viaje a las islas..." (151). Con el uso del imperfecto, las imágenes recordadas por Cata invaden el presente y 
se quedan en él ("muerte imperfecta: ni olvido ni resurrección", según Barthes). La magia, la lozanía y la felicidad, valores absolutamente excluidos en la contemporaneidad sin horizontes que agobia al personaje, se instauran en un nivel discursivo cuyo valor temporal o aspectual es el imperfecto: "En español, el imperfecto, que indica pasado y además acción en suspenso, se desliza más fácilmente que el pretérito simple hacia el terreno de lo irreal". (Reyes, 95)

Idéntica mecánica se observa en el siguiente enunciado de Cata: el imperfecto irradia desde el pasado todo aquello que se vuelve inasible en su presente:

Llegamos a un puerto, muy verde, con casitas de todos colores, trepando las colinas que rodeaban la rada. El cielo del puerto estaba todo lleno de mástiles y velámenes. Gente paseaba en el malecón. Señoras de blanco, niñeras de azul, niñitos de rojo, naranja y celeste. Parada en cubierta, con todo mi cuerpo apoyado en la baranda, mi vista se iba por las casitas del puerto, hasta el bosque de pinos que el viento del mar agitaba en lo alto de la colina (EXALTÁNDOSE) 5 . Trepé por el sendero lleno de sol. El teniente me seguía. Mi corazón agitaba el pecho y la sangre me golpeaba los tímpanos, mientras trepaba, liviana, alegre! Hubiera podido morir de lo excitada que me sentía. Todo mi cuerpo esponjándose en una gran burbuja de ardor! Llegamos al bosque, que era mi meta. Había un muro. No supe lo que era: un fuerte viejo, tal vez, o un convento abandonado. Grandes aves levantaban el vuelo desde las almenas y revoloteaban sobre nuestras cabezas. Y había un poste... ¡Abajo, en el puerto, mis padres me hacían señas! ¡Veía sus pañuelos blancos agitándose en la brisa de la rada! ¡De pronto, perdí mis sentidos! Una dulce sensación de dicha invadía. Todo entraba en mí: el puerto, la brisa, las aves, el brillo del agua. El pasto verde y tierno al alcance de mis manos (ACEZA, TODA AGITADA)...todo penetrando en mí... caliente... brillante... (153)

La revivificación del pasado impregna y satisface el presente mustio del personaje a través de connotaciones y ramificaciones de imágenes pletóricas de vitalidad; todo es naturaleza avasalladora. La totalidad de los tiempos verbales que Cata enuncia en el fragmento referido corresponden a pretéritos. Este hecho evidencia que el hablante manipula el

5 En mayúsculas en el texto. Lo mismo en citas referidas más adelante.

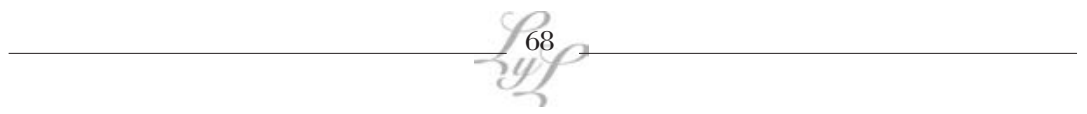


lenguaje para conseguir que este satisfaga sus necesidades comunicativas, las que, en el caso estudiado, se trata de instaurar, en el presente, un pasado en acción desplegada y duradera en el tiempo y que pueda desplazar la contemporaneidad puntual. En otras palabras, la búsqueda del efecto 'mimicry'. Junto con la descripción de este fenómeno, interesa observar la manera cómo se enlaza con la categoría del 'ilinx'. La compatibilidad entre ambas categorías está fundamentada por Caillois (97). Por tanto, el proceso de evasión -verificado en el discurso de Cata- se ve profundamente potencializado en el producto que arroja el simulacro: la búsqueda del vértigo. El lenguaje didascálico así lo demuestra: en la medida que el pretérito vitalizador se instala, discursivamente, en el presente de la hablante, logra el efecto pragmático del arrebato: "(EXALTÁNDOSE)", "(ACEZA, TODA AGITADA)" (52, 53). Es el ímpetu, la pasión, el enajenamiento que olvida y purga la disminución, el fracaso, la derrota.

Exacto mecanismo se da en otro ejemplo, siempre en la reiterativa historia de la mujer, a modo de rito regular y catártico y donde, una vez más, el discurso de Cata se configura en signo ostensible del despojo pasajero de su realidad presente. Consecuencia de este proceso, aparece, en similar figura descrita en los ejemplos anteriores, el abandono y el éxtasis:

Entonces, el puerto! El mar! El brillo del mar, hijo...

Y después, corriendo como un volantín, entre las dunas...con los faldones del abrigo batiendo (...) como grandes alas... gritando!, gimiendo!

\section{LARGO SILENCIO EXHAUSTO. (168)}

El uso exclusivo del gerundio, en este caso, ha logrado que el discurso del hablante traslade e instale, aunque sea por ciertos instantes -los que dura el juego- el pasado. El vértigo, el éxtasis, el 'ilinx', lo revela deícticamente la manifestación de la actitud del sujeto de la enunciación respecto de lo enunciado: "Largo silencio exhausto". La energía vital, impulsiva, resultado del propio "hacer" performativo del locutor, separa la vida corriente y la existencia real mediante situaciones simuladas que emanan, en términos de Barthes, desde "el señuelo agotador de la memoria". (213)

En consecuencia, cada ejemplo descubre el efecto discursivo de Cata asimilado a las categorías que instauran simuladamente otra "realidad", propio de la 'mimicry', y que aniquilan bruscamente, en una suerte de ruptura imposible de reprimir, la percepción real de la conciencia, efecto propio del 'ilinx'. 
El juego como proyecto vital de los protagonistas de Háblame de Laura, de Egon Wolff / Jorge Rueda

\section{La instauración de lo lúdico en Alberto}

En relación con Alberto, el juego compromete una faceta representativa que excede los límites estrictamente discursivos dentro de los cuales se había observado en Cata. Como ya se hizo notar en la presentación de este artículo, los juegos que monta Alberto se ajustan a ciertas recreaciones que se imponen en calidad de rito, regulados y circunscritos por el espacio y el tiempo: "Sala de estar del departamento..." (125); "Fin de otra jornada de trabajo. La misma hora al día siguiente" (139); "Fin de la tercera jornada de trabajo. La misma hora al día siguiente" (156), acota el discurso didascálico respecto del contexto que marca cada una de las tres escenas donde se desarrolla la acción dramática. Es así que, tanto la segunda como tercera escenas muestran representaciones donde, respectivamente, el hombre simula ser víctima de un violento asalto y de un incendio en el interior de la misma habitación:

Entra Alberto despeinado, desarrapado, la chaqueta a medio colgar sobre un hombro, la camisa desgarrada. Tizne en la cara, una canilla a la vista bajo el pantalón enrollado hasta la rodilla; en su camisa y pantorrilla, manchas de sangre. Atraviesa la habitación arrastrándose, botando objetos a la pasada, cae sobre el sofá. Se queja. A los ruidos acude Cata. (139)

[...] un humo tenue comienza a penetrar bajo la puerta de entrada $y$, sin que Cata lo perciba al comienzo, se extiende sobre el piso de la habitación, pesadamente, cubriéndolo todo. Ella huele a quemado, ve el humo y entra en pánico. (156)

Seguida de la información enmarcada por las acotaciones iniciales de ambas escenas, se desarrolla la lúdica dramatización de Alberto, acción que no encierra sino el más puro deseo de jugar. La despreocupada alegría que va contagiando a Cata se convierte en un principio común de diversión. Nuevamente las acotaciones constituyen el marco de la referencia sobre el cual se representa el efecto de la acción de Alberto: la turbulenta alegría que cautiva a los dos personajes. La acción con la cual la mujer reacciona frente a las circunstancias iniciales de la segunda escena es:

Cata: (Grita, viendo a Alberto) Hijo! Qué te pasa?

Alberto muge. Cata va a tocarlo

Alberto: (chilla) No! No me toques! No me roces siquiera! Estoy

herido! Estoy todo hecho tiras!

Cata: Pero qué te pasó?

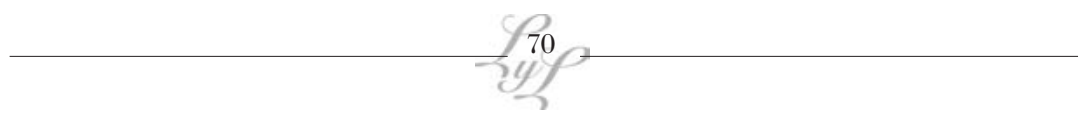


Alberto: (desfalleciente) Me asaltaron!

$[\ldots]$

Alberto: Y ahora tráeme un guatero!

Cata: Sí, hijo, sí!

Cata corre y regresa con el guatero.

Alberto: Pónmelo bajo el traste!

Cata: ¿Por qué ahí hijo?

Alberto: Porque se me heló el poto!

Cata procede con todo cuidado.

Alberto: ... Y ahora, tráeme un paño con hielo!

Cata: ¿Para qué hielo, hijo?

Alberto: Se me heló la cabeza!

Cata corre y retorna con un paño en el que va vertiendo cubito de hielo. Sin embargo, ya viene con dudas.

Alberto: Pónmelo...!

Ella procede.

Alberto (Sonriendo en blanco): Y ahora, que te parece el espectáculo, eh? Grandioso, eh?

Cata: Tú no tienes nada. Me engañaste otra vez, maldito!

ALBERTO RÍE. ELLA LE ARREBATA EL GUATERO Y LO GOLPEA

CON ÉL. ALBERTO EXTRAE UNA BOTELLITA CON "SANGRE" Y LA

MUESTRA. RÍE A DESGAÑITARSE. ELLA, AL FIN, TAMBIÉN CEDE A

LA RISA. CAE JUNTO A ÉL, SOBRE EL SOFÁ (SOFOCADA). (140, 141)

La recreación lúdica que monta Alberto al inicio de la tercera escena -un incendio al interior del departamento- alcanza idénticos efectos: la agitación desordenada, que no persigue más que el placer de jugar (tal como en el ejemplo anterior, no se cita más que la culminación del juego representado por Alberto, en cuanto resultado):

Alberto: Fin de fiesta! Aquí morimos todos! Siempre dije que nuestro fin sería el infierno!

Cata: Volviste a engañarme! Volviste a tomarme el pelo, ratón! Ratón de alcantarilla!

ALBERTO CORRE A GRANDES ZANCADAS HACIA FUERA Y RETORNA CON UN BRASERILLO DE LATA, EN EL CUAL HUMEAN UNOS GANGOCHOS. CAE CON ESO, SOFOCADO DE RISA, JUNTO A ELLA, SOBRE EL SOFÁ, CATA AGARRA UN COJÍN Y LO GOLPEA CON ÉL. AL FINAL. AGOTADA. CAE JUNTO A ÉL RIENDO. (158)

Sin duda que toda "representación" activa otros códigos, entre los cuales el discursivo no siempre es prioritario (ofrecen idéntica 
importancia, por ejemplo, el proxémico y el kinésico). No obstante, lo que realmente preocupa, dentro de los límites que se ha impuesto este artículo, pasa por explicar la acción lúdica no como una dimensión aislada, sino como el aspecto central al interior del proyecto de los protagonistas. En consecuencia, a continuación se examinará la categoría pragmática que se encuentra constantemente presente en el discurso de Alberto y que logra como efecto la alteración y simulación del entorno (la 'mimicry').

Alberto es quien más reitera la marginalidad y derrota que experimenta frente a la vida. Desdeña, así, las condiciones que regulan las costumbres establecidas; él rechaza la estipulación pública (convencional). En función de este marco, se describirá el índice más ostensible mediante el cual este personaje alcanza la disimulación de la realidad. El procedimiento utilizado por Alberto está en correspondencia con el tipo rupturista de su enunciación. La contra-declaración es efecto recurrente en él y es el camino que recorre para manifestar el desprecio por las instituciones sociales. Alberto contradice y transgrede aquello que caracteriza, en general, al recurso discursivo de la declaración. Esta última, para J. Habermas, se entiende como la manifestación que establece correspondencia entre el contenido proporcional y la realidad; por lo mismo, crean las condiciones a las cuales las palabras se refieren. Más obviamente que cualquiera otra clase de actos de habla, "la declaración testimonia el poder del lenguaje para constituir la realidad. Sin embargo, debe existir una institución extralingüística, como la ley, la iglesia, la propiedad privada, el Estado, la misma sociedad, que delimite las posiciones especiales del hablante y del oyente dentro de cada una de las organizaciones instituidas" (378). Sólo en este contexto se manifiesta la declaración, forma a la cual se le suma un papel ilocucionario: "La declaración de intención toma la forma implícita de 'Declaro que...', vale decir, un acto de habla realizado en actitud orientada hacia el entendimiento" (Habermas 393).

La "declaración" conceptualizada en aquellos términos se impugna por la actividad discursiva de Alberto. Este fenómeno se conecta precisamente con el proyecto del personaje: la necesidad de evadir la realidad institucionalizada y su propio estilo de vida. La mecánica establecida por Alberto se desarrolla mediante la notoria violación de la correspondencia entre los diversos contenidos proposicionales del hablante y la realidad puntual. En otras palabras, la contra-declaración. El sujeto de la enunciación se apropia formalmente de un discurso que perturba la realidad estatuida por las reglas de las instituciones extralingüísticas.

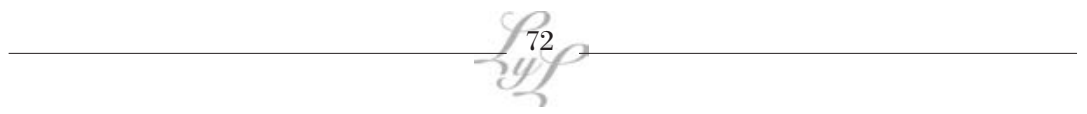


En la segunda escena del texto se descubren varias muestras que evidencian la articulación entre la palabra de este personaje y su voluntad por instaurar otra realidad, la mimicry, a partir de la destrucción (vía contra-declarativamente) de la realidad puntual. Por ejemplo, la formalidad y la circunspección, en cuanto valores públicamente aceptados, se arruinan por la actividad discursiva del hablante:

Alberto: Me perturba la seguridad de que mi carne existe, y de que la lavandería del chino tenga un frente de, exactamente, diez y ocho pasos, vieja... ¡Sí, madre, te estoy tomando el pelo! Tic, un corazón! Tac, la lavandería! Tic, La Avenida España! Toc, el Panteón donde guardan el hígado heroico del Gran Conquistador! ALBERTO LE TOMA LA CARA A CATA ¿Sabes que tú eres la Virgen Santísima, la Virgen del Pilar, La Virgen de los Suspiros, y todas las Vírgenes juntas? LA ABRAZA, TRATA DE RODEARLA ENTERAMENTE EN SU BRAZO... TOCÁNDOLE EL VIENTRE. De modo que ahí, tic, yo estuve alguna vez, escondido el putitas, toc... PONE SU CABEZA CONTRA EL VIENTRE DE ELLA. ¡No te muevas! ¡Déjame escuchar mi sangre en la tuya! (LA MIRA DE PRONTO) ¿Nunca quisiste expulsarme de ahí, vieja? (142)

La contra-declaración transgrede, en este caso, lo establecido institucionalmente como solemne, heroico, religioso, moral. Lo lúdico ("iSí, madre, te estoy tomando el pelo!"), confirmado de manera asertiva por Alberto, relativiza aquello que las convenciones extralingüísticas engrandecen. La tradición históricamente heroica se asimila, en una "realidad" dislocada, a la par de la lavandería. La resonancia a las reglas religiosas, otra institución extralingüística aludida por Habermas, recibe idéntico tratamiento enunciativo: el ritual consagrado a la idolatría de la Virgen María, cuya sugerencia ortodoxa es la pureza de su vientre, se iguala, por una parte, con la maternidad de Cata y, por otra, con el propio hablante, fruto del "virgíneo" vientre de la mujer. En él, Alberto se auto-declara "escondido el putitas", expresión que denota la idea de prohibición pecaminosa que se conecta con la aventura que reitera Cata, a lo largo del texto, con el teniente: "Trepé por el sendero lleno de sol. El teniente me seguía. Mi corazón agitaba el pecho y la sangre me golpeaba los tímpanos, mientras trepaba, liviana, alegre! Hubiera podido morir de lo excitada que me sentía. Todo mi cuerpo esponjándose en una gran burbuja de ardor!" (153). Se agrega la apelación que termina por denegar toda institución religiosa que honra la maternidad: " ¿Nunca quisiste expulsarme de ahí, vieja?". 
La remembranza a los difuntos es otro acto que reconoce dependencia entre la comunidad con el lenguaje, instrumento a través del cual se constituye a sí misma en cuanto compromisos contraídos y obligaciones asumidas. Tal convención, igualmente, se percibe afectada por el esfuerzo determinado del hablante de invertir la realidad:

Alberto: (SONRISA VACUA) Lo que me pasa, hoy día, es que me duele el alma, vieja. Y lo hago en memoria de mi padre, que debe haber sido el hijo de la gran puta.... Siempre me pongo triste cuando me viene su recuerdo y se me llenan las venas de sangre negra...

Entonces réquiem a mi padre!" (143)

La forma más segura que tiene Alberto de destruir y evadir la realidad (el proyecto discursivo asumido por el personaje) es violentando las estipulaciones públicas del lenguaje; en esta oportunidad, la actividad discursiva del hablante invierte un ceremonial y declara un anti-réquiem.

En el siguiente ejemplo, resulta destruido el discurso amoroso. A lo que la institucionalidad ha edificado en función de un lenguaje de la seducción, Alberto manifiesta su experiencia de amor mediante un decir repulsivo, de la no seducción y de la contra-fascinación:

¿Sabes dónde fuimos cuando salimos con Laura la primera vez? Al cementerio... A la niña Laura le gustaba ver las tumbas; al niño Alberto también... Le hable de ti, de la pecera, de la tienda de Lozada, de mi colesterol, y de todos los grandes proyectos nunca realizados... y desde entonces, hemos vuelto un par de veces. Andan los dos entre lápidas, tomados de la mano, y yo le cuento de las películas vistas y ella de las que nunca verá. (147)

Alejado absolutamente del tono erótico, el hablante utiliza un lenguaje que responde al deseo de acoplar el discurso no a la realidad de las instituciones públicas -como sí lo haría la "declaración con intención" en Habermas- sino al proyecto enunciativo que le motiva.

Se tomará, por último, un ejemplo de la escena final. En él, Alberto contradice la alabanza, el prestigio social y el galardón por medio de la burla de otro acto de carácter institucional: el del reconocimiento público:

Lozada me condecoró, hoy día madre!... Hizo colgar guirnaldas de guías usadas y facturas vencidas, de un extremo a otro de la tienda, y vino, y con un gesto teatral, así, me condecoró con una zapatilla de gamuza!... Hoy vendí catorce pares de la hermosa

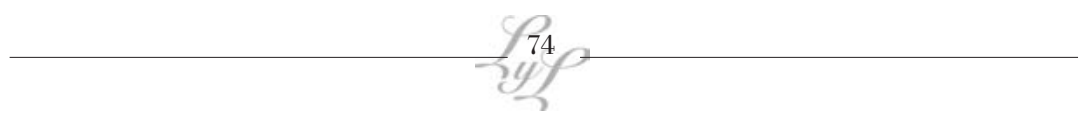


línea italiana, y Lozada vino y trémulo, transtornado de frenética felicidad, me condecoró con una escoba, mamá! (164).

La "condecoración", distinción u honor concedido pública y oficialmente a una persona que ha realizado algún acto especial de valor, se invierte a partir de la palabra del hablante, y se trasmuta en acto ramplón y tosco. La recompensa honorífica que ha instituido la convención social, deja paso a la burla y la humillación: las guirnaldas de guías usadas y facturas vencidas, la zapatilla y la escoba, son los signos ostensibles con los cuales el hablante trastoca la denotación tradicional de medallas y galardones.

El sello de unidad e identificación de cada una de las muestras discursivas anteriores es inescapable: la realidad que disimula y evade Alberto se encuentra institucionalizada por formas específicas del lenguaje. La contra-declaración es la herramienta discursiva cuyo efecto enunciativo consigue el desvanecimiento del entorno. Este último rasgo se acrecienta en la medida que los actos funcionalizados públicamente no sean tomados en serio. Alberto conoce sobradamente estas condiciones. En este sentido, hace uso de una categoría absolutamente pragmática: la "connivencia". En este procedimiento, el sujeto de la enunciación toma el lugar de otro hablante y la forma de un discurso en especial para que, precisamente, el discurso así producido se autodestruya (Maingueneau, 159). El resultado se traduce en el desmoronamiento de los procedimientos convencionales del discurso y la aparición de la 'mimicry' en cuanto culminación absoluta y como dimensión neutralizadora de la realidad. Hacia el final de la escena tercera, después de la manifestación de todos los ejemplos citados. Alberto exclama:

Alberto: Juguemos! Vamos, ven a mis brazos!

LA ABRAZA.

Que no ves que pueden tomar nuestras vidas, vieja, pero no nos pueden quitar el aire que circula por los montes!

LA LEVANTA Y COMIENZA A GIRAR CON ELLA.

Hay un viento libre y hermoso, que gira, vieja!

ELLA NO SE RESISTE... COMIENZA A ENTRAR EN ELJUEGO.

Un viento que gira y que es nuestro! Carbón cae sobre los techos pero bajo la tierra fermenta la semilla, vieja!

GIRA CON ELLA, EN VILO.

Tú y yo, somos un globo, vieja!

Un globo! Un globo que gira y gira! Vuela, vieja, vuela! Vuela conmigo! 
El juego como proyecto vital de los protagonistas de Háblame de Laura, de Egon Wolff / Jorge Rueda

Vuela! Vuela!

CAEN EXTENUADOS SOBRE EL SOFÁ. $(166,167)$

Alberto ha abierto el camino para la instalación de un espacio lúdico, límite donde las leyes, instituciones y formalismos públicos de la vida social quedarán reemplazadas por otras donde predomina la disimulación de la realidad puntual: "Juguemos! Vamos, ven a mis brazos!... Que no ves que pueden tomar nuestras vidas, vieja, pero no nos pueden quitar el aire que circula por los montes!... Tú y yo, somos un globo, vieja! Un globo! Un globo que gira y gira! Vuela, vieja, vuela! Vuela conmigo!" (168). Los proyectos de los protagonistas se encuentran en este punto del texto. Ambos terminan por conformar una dimensión de franca irrealidad en relación con las circunstancias contingentes del mundo y de la vida, figura que encuentra correspondencia con la 'minicry', categoría cuyo fundamento "descansa sobre el hecho de que el sujeto juega a creer que él es distinto de sí mismo y olvida, disfraza, se despoja pasajeramente de su realidad para fingir otra" (Caillois, 36). El departamento, demarcación del espacio lúdico, se articula en este "otro mundo" que ha generado Alberto a partir de su palabra:

\section{ESTÁN LOS DOS, UN RATO, ABRAZADOS.}

Estamos tú y yo, vieja, y eso es algo que nadie nos podrá quitar. Mientras tú y yo estemos aquí, veremos pasar los días, y esta habitación se llenará de tu respiración y de las mías... y haremos un mundo de esta pieza....

... Yo, en tanto, conquistaré Arabia, vieja! Con Lawrence y su corte de estranguladores!... (169)

La neutralización del entorno y la recreación de "otro mundo en la pieza" no requiere para su validez de la mediación de los procedimientos públicos, pues está enraizado en una ficción, en la "ilusión" (palabra que no significa otra cosa que entrada en juego: "in-lusio") de no estar atado a reglas ni sanciones y separarse, por el tiempo que dura la acción lúdica, de la percepción de la realidad.

Solamente en el contexto que se acaba de describir, se integra de modo coherente la serie de juegos que ambos interlocutores despliegan en el interior del departamento: la taza de "café" que Cata le hace beber a Alberto y que resulta ser pura salmuera (inicio de la Escena I, p. 126), el "asalto" del cual es víctima Alberto (inicio de la Escena II, pp. 139141); la persecución que este último hace a su madre, transfigurado en "Tarzán" y "gorila" (Escena II, pp. 147-148); la broma del pantalón

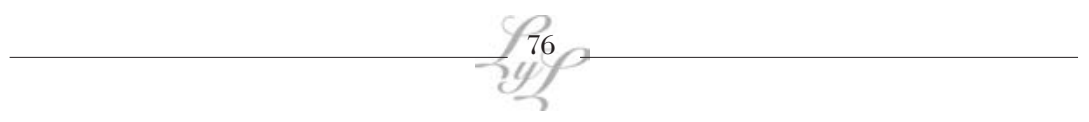


(Escena II, p. 153), y, por último, la simulación de incendio (inicio de la Escena III , pp. 156-158). En concreto, estas manifestaciones lúdicas se encuentran situacionalmente demarcadas por el soporte básico que las mueve: el proyecto discursivo de los hablantes.

Como alcance final, se mostrará cómo se integra en este proceso, de franca des-realización del entorno, la categoría del 'ilinx'. A través de este principio, los hablantes alcanzan el arrebato y la fascinación propicios para revertirse a sí mismos y superar aquella desmedrada condición de vida que les hostiga. Si se revisan las citas referidas a lo largo del artículo, se descubrirá, en la mayoría de ellas, un indicador acotado por el discurso de la didascalias: el abrazo que liga a los interlocutores durante y después de los juegos. Tanto la segunda como tercera escenas finalizan con este gesto de la pareja. Se suma a esta referencia otro índice análogo: las veces en que Alberto se arrima el regazo de Cata y aquellas en que la mujer se cobija junto al hijo ${ }^{6}$. Ambos gestos se articulan plenamente al sistema de correlaciones internas que se contextualizan al interior de la situación de discurso que se ha descrito como proyecto vital de Alberto y Cata. Así, el abrazo, en cuanto gestualidad de cierre de los personajes, se encuentra con la 'mimicry' y el 'ilinx'. Respecto de aquel, Barthes expresó:

[El abrazo] es un enlazamiento inmóvil: estamos encantados, hechizados: estamos en el sueño, sin dormir; estamos en la voluptuosidad infantil del adormecimiento (...), es el retorno de la madre (...). En este incesto prorrogado, todo está entonces suspendido: el tiempo, la ley, la prohibición: nada se agota, nada se quiere: todos los deseos son abolidos, porque parecen definitivamente colmados. $(24,25)$

En concordancia con Barthes, el abrazo es una acción cuyo código desmantela el razonamiento sistemático y logra el deslizamiento de la experiencia social, colectiva y real. El abrazo es un movimiento que sale de las estructuras y va hacia la autonomía, se escabulle del control y se instala en la magia, el enajenamiento, el vértigo, el "ilinx". En efecto, tal gesto es el índice culminante de la actividad discursiva de los interlocutores y es por esta razón que se le atribuye en este análisis, como propiedad, el provocador de un efecto performativo global: no es coincidencia que el texto finalice con un enunciado acotacional donde, precisamente, sea el abrazo el signo postrero de los protagonistas:

6 pp. 137, 141, 155, 163, 164, 167, 168, 171. 
El juego como proyecto vital de los protagonistas de Háblame de Laura, de Egon Wolff / Jorge Rueda

\section{LA SOMBRA DE LOS PECES, NADANDO EN SU PRISIÓN TRASLUCIDA, SE PROYECTA CONTRA EL MURO ENFRENTE, ILUMINADA A CONTRALUZ POR EL REFLEJO AZULADO DE LA PANTALLA DEL TELEVISOR. LA PAREJA PERMANECE ABRAZADA, VIENDO LA TELE, MIENTRAS CAE EL TELÓN. (171)}

El final de la obra ratifica las categorías lúdicas que se han examinado a partir de los proyectos, actividad discursiva y acciones de los protagonistas: un permanente acto de des-realización. En este marco, el juego representa, en la creación Háblame de Laura, la posibilidad que tienen los personajes del texto para soslayar el mundo que les hostiga $y$, en consecuencia, evadirlo.

Por lo anterior, el efecto 'mimicry' en Háblame de Laura adquiere suficiente carga semántica para comprender la inversión que hacen sus protagonistas de la realidad en que viven. Lo imaginado y lo soñado nutren la dinámica lúdica; así, los personajes cierran la puerta al orden real. El espacio socialmente institucionalizado interfiere de manera inflexible en los protagonistas. Como flanco de ataque, se empeña en derrumbarlos. Representa, por lo mismo, el "no - lugar" de sus existencias (Augé, 2000), vale decir, un ámbito anónimo, difuso y fragmentario donde lo humano se niega y se clausura. Por lo mismo, el juego y todas las acciones delirantes, enajenadas y fantásticas que de él emanan, son valiosas y deseables justamente por su contraste con la realidad, cuyo valor rechazan y, por ende, consideran detestables y sinsentido. Este aspecto de la composición de la obra respalda lo que en el autor pasa a ser una constante como medio de interpretación del mundo: la fuga hacia ámbitos de la fantasía en una dramaturgia de orientación realista. La incorporación del juego muestra cómo "por sobre el realismo pasa un apetito de imaginación [...] o de atmósferas oníricas y distorsionadas que desflecan los bordes de lo real" (Rama, 173).

\section{Conclusiones}

El análisis precedente evidenció, en primer lugar, el objetivo del proyecto de articulación pragmático-discursiva de los protagonistas: la necesidad de separarse de la vida corriente y el consiguiente anhelo de conformar una segunda "realidad", lúdica, de franca separación con las circunstancias de la vida ordinaria que experimentan. En virtud de esto último, se confirmó que únicamente la dimensión enunciativa generada al interior del texto, y que se manifiesta en los discursos de los hablantes,

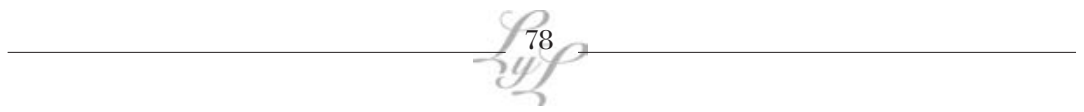


propicia la sustitución del entorno -cargado, para éstos, de fracasos y derrota- por un espacio lúdico como placebo. Este fenómeno se logra a partir del reconocimiento de la intencionalidad ilocucionaria que se encuentra presente en la actividad discursiva de los hablantes. En este contexto, la opción por el juego representa la posibilidad que tienen los interlocutores para soslayar la realidad social y sus propias historias de vida que les han convertido en personajes sórdidos y amargos. Tal condición se desvanece en la medida en que ella, discursivamente, no es tomada en serio (como lo hace la palabra de Alberto) o se anula con la fascinación del pasado (como lo hace la palabra de Cata).

Solamente el lenguaje, conformador de "reglas constitutivas", invierte la realidad institucionalizada a través de la contra-declaración, forma que se convierte en el índice más ostensible del discurso que profiere Alberto, y rehúye el presente puntual por intermedio del tiempo imperfectivo, señal más identificatoria respecto de la enunciación de Cata. El resultado de tales estrategias enunciativas se transforma en el hacer perfomativo de los hablantes, cuyo efecto se resume, precisamente, en la realización exitosa -aunque sea por los instantes que dura un juego- del proyecto discursivo de los hablantes: simular y desplazar la realidad mediante el principio regulador de la 'mimicry'.

Por último, la suspensión de las normativas instituidas públicamente y del presente o contemporaneidad en el cual están inmersos los personajes, lleva a los hablantes a un estado de arrebato y enajenación que termina por confirmar el aniquilamiento de la realidad vale decir, el 'ilinx'.

\section{Bibliografía}

Augé, M. (2000). Los no lugares. Espacios del anonimato. Una antropología de la sobremodermidad. Trad. Margarita Mizraji. Barcelona: Gedisa.

Barthes, R. (1974). Fragmentos de un discurso amoroso. Trad. Eduardo Molina. México, Siglo Veintiuno.

Caillois, R. (1958). Teoría de los juegos. Barcelona, Seix Barral.

Díaz, S. (2008). "Háblame de Laura y la tragedia de lo cotidiano". Revista electrónica La Santísima Trinidad de las Cuatro Esquinas. http://trinidaddecuatroesquinas.blogspot.com/2008/12/ hblame-de-laura-y-la-tragedia-de-lo.html Consulta: 2011-12-11 
El juego como proyecto vital de los protagonistas de Háblame de Laura, de Egon Wolff / Jorge Rueda

Gadamer, H. (1993). Verdad y Método I. Trad. Ana Agud Aparicio y Rafael de Agapito. Salamanca, Sígueme.

Habermas, J. (1989). Teoría de la acción comunicativa I. Racionalidad de la acción y racionalización social. Buenos Aires, Taurus.

Huizinga, J. (1990). Homo ludens. Madrid, Alianza.

Maingueneau, D. (1976). Introducción a los métodos del discurso. Buenos Aires, Hachette.

Morel, C. (1988). "Háblame de Laura: Estructura dramática circular y pulsión a la repetición". Revista Apuntes de Teatro No 96 (Otoño).

Rama, A. (2008). La novela en América Latina. Panoramas 1920 - 1980. Santiago de Chile: Ediciones Universidad Alberto Hurtado.

Reyes, G. (1993). La pragmática lingüística. El estudio del uso del lenguaje. Barcelona, Sígueme.

Skármeta, A. (1971). "La burguesía invadida: I. Egon Wolf”. Revista Chilena de Literatura No 4 (Otoño).

Wolff, E. (1988). Háblame de Laura. Revista Apuntes de Teatro, No 96, (Otoño).

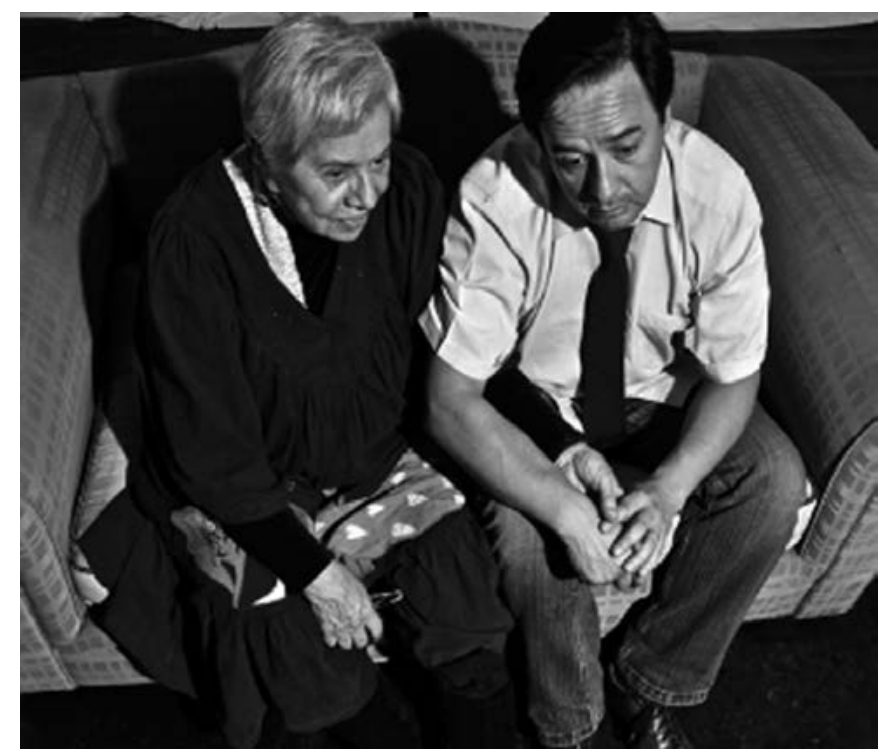

Alberto y Cata en el montaje de 2011 (junio 23 / agosto 6. Teatro Mori Bellavista. Santiago de Chile. Con Claudio Arredondo y Gabriela Medina).

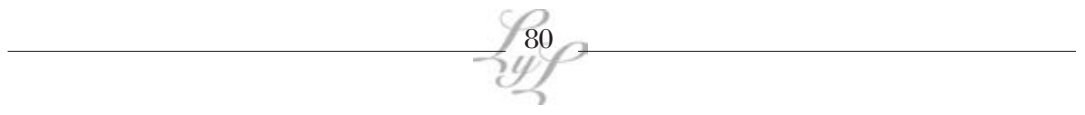

